\title{
Elenco de proposições sobre velhice e vértices em Psicanálise ${ }^{1}$
}

\section{Antonio Sapienza ${ }^{2}$}

$$
\text { - I - }
$$

"O que é a velhice?

Planta que cresce em duas direções:

A aurora da infância

A noite da morte."

Adonis - "Guia para uma viagem através das florestas do sentido" - 1988 - Poemas Companhia das Letras, 2012 - p. 219.

$$
\text { - II - }
$$

"O que é a morte?

Carro que leva

Do útero da mulher

Ao útero da terra."

Adonis - "Guia para uma viagem através das florestas do sentido" - 1988 - Poemas Companhia das Letras, 2012 - p. 218.

Freud (1926 - SE XX - 'Inibição, Sintoma e Angústia') destaca duas cesuras básicas para cada ser humano: a cesura do nascimento e a cesura da morte. Entre as duas cesuras desenvolve-se o arco da existência humana. A primeira cesura envolve o trauma do

\footnotetext{
${ }^{1}$ Este trabalho foi apresentado na mesa "Envelhecimento temido: tempo desconcertado" com Alberto Frisoli Jr. no I Simpósio Bienal "O mesmo, o outro: Psicanálise em movimento" da Sociedade Brasileira de Psicanálise de São Paulo.

${ }^{2}$ Analista Didata da Sociedade Brasileira de Psicanálise de São Paulo.
} 
nascimento e a segunda o suspense da experiência de nossa inevitável mortalidade. Seguemse outras cesuras em ciclos da vida: infância, adolescência, juventude, meia-idade, casamento, velhice.

Em 1934, aos 78 anos de idade, Sigmund Freud [1856-1939] declara em uma entrevista ao escritor italiano Giovanni Papini [1881-1956]: "sou cientista por necessidade, não por vocação. Na verdade minha natureza é de artista. Desde a infância o meu herói secreto é Goethe. Gostaria de ter sido poeta, e a vida inteira tive vontade de escrever romances”. Ele contou a Papini que na época em que foi estudar com Charcot em Paris (1885-1886) seus interesses estavam voltados para os maiores movimentos literários do seu tempo; e que os adaptara - simbolismo, naturalismo e romantismo - para a teoria psicanalítica: "eram a inspiração de todo o meu mais recente trabalho". Colecionara documentos humanos e deralhes tratamento natural e científico. Os simbolistas o haviam alertado para a importância dos sonhos e da linguagem. Com o romantismo aprendeu a dar ênfase ao eu e à sensibilidade. Por fim, de seu antigo interesse pelos clássicos lembrara-se dos mitos de Édipo e Narciso.

Martin, Jay - "Quem vou ser desta vez?" - tradução de Jurandyr B. Nogueira - São Paulo Ed. Siciliano, 1990 - p. 173.

A partir de leitura reflexiva sobre 'Antigona' [442 a.c] de Sófocles [497 a.c - 406 a.c], Freud consegue elaborar o 'Livro dos sonhos' (1900).

$$
\text { - IV - }
$$

“Ognuno sta solo sul cuor della terra

traffito da un raggio di sole ed è subito sera"

Quasimodo, Salvatore 1942

“Cada um de nós está só sobre o coração da terra 


$$
\begin{aligned}
& \text { transpassado por um raio de sol } \\
& \text { e subitamente é noite" } \\
& \text { (tradução do autor). }
\end{aligned}
$$

Quasimodo, Salvatore [Módica 1901 - Nápoles 1968] - poeta e escritor expoente do hermetismo. Prêmio Nobel de literatura em 1959, em que se destacam outros ensaios sobre nossa transitoriedade e os terrores da guerra.

O leitor encontrará em Freud 'Sobre a Transiência' (1916 - SE XIV) valiosa contribuição sobre nossa efêmera vida.

$$
\text { - V - }
$$

O cientista Galileu Galilei [1564 -1642] declara, nos intermináveis confrontos com a inquisição, que 'a verdade é filha do tempo e não da autoridade, mas a dúvida é o começo da sabedoria'.

Poder-se-ia recordar neste momento as observações de Wilfred R. Bion [1897-1979] principalmente aquelas descritas em 'transformações' (1965) ao destacar a incessante busca do vínculo de conhecimento [Knowledge] na direção de 'Deus, Infinito, Realidade Última”, que vem a ser de modo conciso $+(\mathrm{K}) \rightarrow$ ' $\mathrm{O}$ '. Conhecimento da verdade requer maturação pelo vetor temporalidade diante do universo em expansão. Os desafios propostos pela teoria do Big Bang como conjectura do inicio do universo têm requerido o uso específico de exploração do universo em expansão através de sondas espaciais da Hubble.

A dupla analítica a cada sessão visa apurar a capacidade de aprender da experiência emocional em clima de intimidade; tanto o analisando quanto o analista usam suas sondas específicas visando ao universo desconhecido diante da oscilação representada basicamente pela oscilação das posições esquizoparanoide e depressiva representadas sinteticamente por Ps $\leftarrow \rightarrow$ D. A própria condição do encontro na pesquisa e investigação em psicanálise 
desencadeia turbulência emocional, a qual vem a ser inevitável para a parceria conseguir crescimento mental.

O livro 'Controvérsias Freud-Klein 1941-1945' foi publicado em 1991 e se acompanha de depoimentos por dois psicanalistas: 'uma contribuição exemplar à história de ideias em psicanálise' (Julia Kristeva - data de nascimento 1941, agora com 77 anos) e 'o mais importante documento da psicanálise pós-freudiana' (Andre Green - 1927-2012).

Melanie Klein (1881-1960) ressalta a importância da posição depressiva e o valor das manifestações defensivas de natureza psicótica, as quais têm como fundamentação os movimentos derivados dos desastres mentais por 'Splitting'. Tais resíduos de antigo desastre primitivo residem em camadas subterrâneas. O analista deverá acompanhar o paciente de modo delicado e firme na abordagem de tais camadas. A análise vai requerer dose crescente de paciência e segurança no desenrolar da abordagem destas camadas mais profundas. $\mathrm{O}$ modelo psicanalítico se aproxima de metodologia semelhante aos paradigmas nos estudos de geologia, requerendo posterior microscopia. Em certos momentos, Bion compara tal metodologia ao uso de delicado pincel de pelos de cauda de elefante que limpa suavemente o material selecionado para num segundo tempo poder montar e colorir lâmina da amostra colhida no campo da pesquisa, a qual passará a sofrer tratamento semelhante ao que se obtém a partir de uma biópsia cirúrgica, dando continuidade à pesquisa com estudo microscópico, portanto em momento diferenciado do campo original. $\mathrm{O}$ analista poderá, fora da sessão, realizar exercícios de 'grade' própria para assim estudar enganos e também 'sonhar com rêverie' elementos de sua contratransferência. Trata-se de um cuidado para manter a vitalidade que dá suporte e atualização às funções de capacitação adequada como 'continente com rêverie'. Penso que haja certa equivalência entre 'Continente com Rêverie' e a função de "Holding e Interpretação" (Winnicott, 1972 - post-mortem) na proposição de Donald Winnicott [1896-1971] ao destacar a seguinte tríade: o 'Gesto Espontâneo', o 'Objeto Transicional' e a 'Dependência'.

As contribuições de Sandor Ferenczi [1873-1933] contêm interessante e original abordagem de memórias traumáticas, cujo teor é revelado principalmente em notas do "Jornal Clínico" 
(1932). Ferenczi valoriza a linguagem poética em busca de perdão, o qual irá se contrapor aos jogos perversos de natureza vingativa junto à adição ao desprazer, para conseguir desmanchar o núcleo da retaliação, do qual emanam as leis de natureza sadomasoquista. Suas 'reflexões sobre o masoquismo' (1932) atingem de modo eficaz e contundente o 'terrorismo do sofrimento' ao propor o reviver do conflito traumático como condição para se poder usar um harpão e assim afastar os poderes destrutivos de medusa internalizada ('A Mãe Morta' na proposta modelar de Andre Green - 1983).

Ao isolar a posição depressiva, Klein pôde estudar os fatores de evolução da posição depressiva, cujo êxito sendo bem sucedido na parceria analítica, irá possibilitar crescente capacitação na arte de gerar e também partejar 'pensamentos de salvação e de restauração', no dizer de Wilfred Bion. O final dos seminários italianos em Roma (Julho - 1977) é surpreendente ao Bion declamar o poema 'Ozymandias' de Shelley [1792-1822].

Esta direção privilegia até o fim de nossas vidas o foco de conflitos entre nossas partes psicóticas de personalidade (PP) e partes não psicóticas de personalidade (PNP). Tal atenção e cuidados são requisitados para as escolhas que possam preservar vigorosa autonomia e vigilância para nos libertar de rapto como aprisionamento das PNP pelas violências de gang de nossas PP. Em 1937, Freud destaca as características desta recomendação através de seu texto 'Análise Terminável e Interminável' (SE XXIII), ao clamar por nossa capacidade do mapear junto ao analisando uma 'construção' bem como também conter intempestiva pressa em interpretar, como um colapso doentio de tudo interpretar, ser dotado da onisciência de sujeito de suposto saber que tudo conhece e a tudo se expõe. Convém ter em mente as metáforas de combates entre Édipo e os enigmas engendrados pela astuciosa esfinge, assim como no momento de uma crise 'política' entre o rei Édipo e o adivinho Tirésias, em razão da 'peste' mortífera, que assola a cidade de Tebas. Realizar constante oscilação entre Narcis-

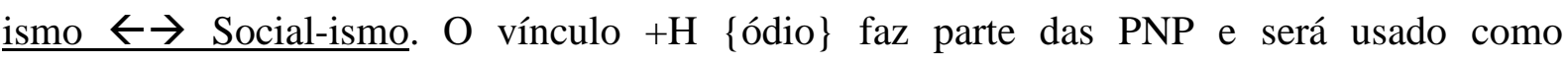
indignação contra mentiras, ilusão e falsidades. 
De um modo que ainda possa requerer mais precisão tais componentes, que pude delinear até este momento, desenham um elenco do cotidiano analítico. Solicitam ainda a preservação e escolha de hábitos mentais que não se restringindo unicamente à sala de análise poderão servir de caminhos para permitir e favorecer a passagem de mudanças catastróficas para mudanças criativas. A leitura de 'Memória do Futuro' (Bion, 1991) é extremamente valiosa e exemplar como autobiografia, que servirá para apurar intuição treinada psicanaliticamente. São parâmetros para evitar que o analista se torne um assassino de perguntas não apenas do paciente.

Talvez a recomendação de fino trato analítico requeira a conjunção das virtudes de prudência e ousadia em harmonia bem dosada. A investigação no diálogo analítico requer clareza em distinguir os seguintes vértices que prevalecem na sessão em andamento: científico, estético,

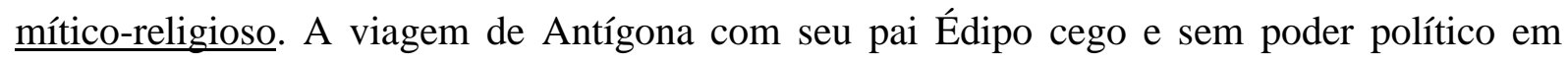
busca de uma tumba desconhecida em Creta poderá constituir modelo de natureza míticoreligiosa em que o deus Teseu colabora como suporte face às escolhas diante das tragédias e do destino, em que o usurpador Creonte ao final desfalece no protagonismo de trágico papel de 'eminência parda'. Breve síntese é exposta em ‘A Compaixão e a Verdade' ('Cogitações' Bion, 1960 - p. 136 - Copyright 1992). 